\title{
Gestão de qualidade do ensino básico em Moçambique: Um estudo em escolas primárias e públicas
}

\begin{abstract}
RESUMO
O artigo busca analisar a gestão de qualidade do ensino básico de Moçambique como forma de contribuição para a melhoria no processo de ensino aprendizagem em três instituições de ensino primário. Foram pesquisados professores e diretores escolares centrando-se na análise de conteúdo e de documentos oficiais do Governo moçambicano. Como técnica para coleta de dados utilizou-se entrevistas com roteiro semiestruturado, optando-se pela abordagem qualitativa. As variáveis analisadas foram mecanismos de qualidade, competência dos diretores e professores e, perfil e formação dos mesmos. Os resultados mostram os fatores considerados pertinentes para melhorar a qualidade de educação, como políticas mais efetivas de orientação ao aluno, formação continuada e integrada dos professores, e profissionais das escolas, condições de trabalho, gestão democrático-participativa e implementação de sistema de avaliação. Constatou-se que uma melhor gestão é importante para um melhor desempenho das escolas e dos alunos, exigindo do diretor esforços para um melhor controle e análise do processo dentro e fora da sala de aula.
\end{abstract}

Palavras-chave: Gestão de Qualidade. Ensino Básico. Moçambique. Escola Primária.

\author{
Joana Carlos Beira \\ joanabeira@yahoo.com.br \\ Mestre em Administração \\ Universidade do Vale do Itajá (UNIVALI) \\ Sandra M. Lohn Vargas \\ sandrabiblio@hotmail.com \\ Doutoranda em Administração \\ Universidade do Vale do Itajaí (UNIVALI) \\ Cláudio Reis Gonçalo \\ claudiogoncalo@univali.br \\ Doutor em Administração \\ Universidade do Vale do Itajá (UNIVALI)
}




\section{INTRODUÇÃO}

A educação é um elemento indispensável e constituinte das relações sociais que contribuem contraditoriamente para a transformação e a manutenção dessas relações, na qual destaca-se a escola como um espaço institucional de produção e de disseminação do saber sistemático e historicamente produzido pela humanidade (DEMO, 1996; DIAS, 2001; DOURADO; OLIVEIRA, 2007).

Moçambique é uma ex-colônia portuguesa a qual se tornou independente em 1975, herdando de Portugal uma longa história e experiência educativa. Após a independência, o país herdou condições econômicas e sociais muito precárias deixadas pelos portugueses, fazendo com que o primeiro Governo moçambicano traçasse, até o final dos anos 80, estratégias de transformação socialista da sociedade e implantasse programas amplos na área de educação, saúde e habitação (EDUARDO, 2012).

Logo após a independência, Moçambique viveu 16 anos de guerra civil, cujo término foi em 1992 com a assinatura do Acordo Geral da Paz, dando início ao processo de democratização e, como consequência, a realização das primeiras eleições multipartidárias em 1994, seguida por outras eleições em 1999, 2004, 2009 e 2014.

O relatório publicado pela AfriMAP e a Open Societylnitiative for Southern Africa aponta que as políticas educativas, incluindo os sucessos e os desafios, resultam, em parte, de uma longa história da experiência educativa deixada pela colônia portuguesa e das escolhas políticas da Frente de Libertação de Moçambique (FRELIMO) desde a luta de libertação no período de 1960 e 1970 (EDUARDO, 2012).

$\mathrm{Na}$ era colonial o governo português não tinha nenhum interesse em educar o povo africano, procurava implantar nas colônias os sistemas de assimilação que objetivava "europeizar" o povo dominado, aculturando-o através da escola ou por outro meio de difusão e propaganda do seu aparelho ideológico (GOLIAS, 1993).

Percebido isso, o governo definiu como prioridades do país, após a independência, a expansão, promoção e nacionalização dos principais serviços sociais, entre eles a educação, passando o Estado a ser o único fornecedor de serviços no setor da educação e fazer da educação não apenas um direito, como também um imperativo para o desenvolvimento nacional com vista a alcançar a meta de, até 2015 , oferecer o ensino primário para todas as crianças em idade escolar.

Não obstante, o esforço que se empreende para atingir as metas de expandir e oferecer uma educação de qualidade a todas as crianças em idade escolar, não tem surtido muito efeito. Observa-se que, com o passar do tempo os gastos do setor da educação aumentam, ao contrário dos recursos alocados que reduziram na mesma proporção, contribuindo deste modo, com a queda da qualidade dos serviços de educação e para que haja um impacto insignificante nas reformas introduzidas no setor educativo (EDUARDO, 2012).

Neste artigo procura-se refletir aspectos que contribuam para a avaliação da qualidade do ensino básico em Moçambique por meio de processos de gestão, como o papel dos diretores, professores e a comunidade em geral na contínua busca de melhoria de qualidade educacional. Nesse sentido busca-se responder a seguinte pergunta de pesquisa: Como a gestão de qualidade do ensino básico de Moçambique pode contribuir para a melhoria no processo de ensino aprendizagem?

Dessa forma, o presente artigo tem como objetivo analisar a gestão de qualidade do ensino básico de Moçambique como forma de contribuir para a melhoria no processo de ensino aprendizagem em três instituições de ensino primário. Foram pesquisados os professores e diretores escolares, por meio de entrevistas, e nos baseamos também na análise de conteúdo e de documentos oficiais do Governo moçambicano que abordam a temática de qualidade de educação no nível básico.

\section{FUNDAMENTAÇÃO TEÓRICA}

O conceito de qualidade tem vários significados, de acordo com diferentes capacidades valorativas, e tem sido muito utilizado no processo produtivo; por isso, não se tem uma ideia clara do que seja qualidade entre os educadores, caindo em falsos consensos e criando grande confusão para os gerentes. Para tanto, a compreensão e as atividades relacionadas à mesma são fatores primários para o sucesso estratégico (GARVIN, 1992; XAVIER, 1996; LONGO, 1996; SLLIS, 2002; STEPHEUS, 2003; OLIVEIRA; ARAUJO, 2005; LIBÂNEO, 2013). 
Pelo fato de não se chegar a uma noção do que seja qualidade de ensino, Oliveira e Araújo (2005) destacam que há no Brasil três formas de percepção quanto à qualidade educacional: Primeira, a qualidade determinada pela oferta insuficiente; Segunda, a qualidade percebida pelas disfunções no fluxo ao longo do ensino fundamental; Terceira, por meio da generalização de sistemas de avaliação baseados em testes padronizados (MOÇAMBIQUE, 2012).

\subsection{Gestão de Qualidade na Educação}

No contexto educacional, a implantação de uma escala de qualidade pressupõe a apreensão de um conjunto de determinantes que interferem nos processos no âmbito das relações sociais mais amplas que envolvem questões macroestruturais (concentração de renda, desigualdade social, ou educação como um direito); questões de análises de sistemas e unidades escolares, e processos de organização e gestão do trabalho escolar (condições de trabalho, processos de gestão da escola, dinâmica curricular, formação e profissionalização docente) (DOURADO; OLIVEIRA, 2007).

Para Gadotti (2013), sob a ótica das Nações Unidas, a qualidade é percebida como a categoria central do novo paradigma da educação sustentável e deve ser acompanhada da quantidade. A educação está intimamente ligada ao bem estar de toda a comunidade e o contínuo investimento na formação dos professores, pois, não pode haver a qualidade na educação sem a participação da sociedade na escola. Para o autor, tanto a escola como as universidades precisam fundamentalmente de três condições básicas: professores bem formados, como elementos chave e referência estratégica da qualidade, condições de trabalho e um projeto político pedagógico.

Os métodos gerenciais para organizações privadas podem ser aproveitados para mudar a gestão escolar, afirma Dias (2001). Contudo, a implementação dos programas de melhoria de qualidade exige a participação da gestão de todos os funcionários, na empresa ou na escola, observando os seguintes quesitos:

a) Grande envolvimento dos professores e funcionários na gestão e na tomada de decisão e delegação de responsabilidades a todos;

b) Liberdade de ação para cada setor, treinando professores, funcionários e gerentes com capacidade de liderança;

c) Técnicas preparatórias;

d) Comprometimento de todos com a qualidade;

e) Análise contínua do funcionamento e de novos métodos.

As ações de qualidade na escola acontecerão aos poucos, a partir do momento em que pessoas (professores e funcionários) envolvidas com o processo de ensino aprendizagem assumam responsabilidades de autonomia nos projetos desenvolvidos pela escola e sintam a necessidade de mudar (DIAS, 2001).

A qualidade na educação pressupõe o envolvimento e a participação de todos os intervenientes da comunidade escolar, desde as instâncias superiores atéa comunidade em geral. Os responsáveis pela gestãoescolar devem dar oportunidade para o envolvimento da comunidade (interna ou externa) da escola impulsionando e agindo de forma mútua e conectada. A democratização do poder e o aperfeiçoamento dos recursos humanos levam, não somente a valorização e motivação dos intervenientes da educação, como também a uma participação ativa e a melhoria de desempenho das atividades com vista ao alcance de um objetivo comum, a melhoria da qualidade na educação (DIAS, 2001; DONEL et al., 2001; DOURADO; OLIVEIRA, 2007).

A definição de dimensões que representam a qualidade na educação é importante por serem consideradas como fator de referência analítica e política em relação à melhoria do processo educativo, à consolidação de mecanismos de controle social da produção, à implantação e monitoramento de políticas educacionais e de seus resultados, com o propósito de produzir uma escola de qualidade socialmente referenciada.

Entretanto, percebe-se que várias são as dificuldades na definição de um padrão de qualidade, envolvendo deste modo aspectos que relaciona a quantidade mínima de aluno/ano, custo/aluno, relação aluno/professor, entre outros (DOURADO; OLIVEIRA; SANTOS, 2009; DOURADO; OLIVEIRA, 2007).

A qualidade da educação se expressa na articulação das dimensões para a concretização de uma política educacional voltada para a segurança de uma escola de qualidade para todos, em todos os ciclos e níveis, e que orientem também o processo ensino aprendizagem e sejam desenvolvidas em comum acordo com 
as ações direcionadas à superação da desigualdade socioeconômica e cultural, presente em cada região, o que pressupõe a qualidade dos processos educativos e, consequentemente, a aprendizagem dos alunos (DOURADO; OLIVEIRA; SANTOS, 2009).

\subsection{Formação de Professores, Gestores Escolares e o Entendimento dos Processos de Gestão de Qualidade da Educação}

A literatura indica que a formação docente deve ser pensada como um aprendizado profissional ao longo da vida, envolvendo profissionalmente os docentes, pois, ao se conhecer melhor e compreender o seu trabalho possibilita a descoberta de caminhos eficazes para alcançar o ensino de qualidade e reverter numa aprendizagem significativa para os alunos (LÜCK, 2009; FONTANIVE; KLEIN, 2010; ANDRÉ, 2010).

A presença do professor representa o elo entre a escola e a sociedade, destacando-se assim, a importância do papel deste profissional como propulsor para responder a procura de novas concepções de educação. Uma vez citada, a falta de preparo dos professores é apontada em vários documentos como uma das causas que mais contribui para o insucesso escolar dos alunos (MICHELS, 2006).

Não existirá ensino de qualidade, reforma educativa e inovação pedagógica, sem antes melhorar a formação de professores (NÓVOA, 1995). Aspectos esses que se fazem sentir em Moçambique através da Política Nacional de Educação - Resolução n 8/95, de 22 de Agosto, que estabelece alguns princípios básicos em que se deve basear a formação, quer inicial e/ou em serviço dos professores.

Destaca-se a necessidade de trazer para dentro das instituições de ensino o conceito de educação ao longo da vida que vise criar uma mudança de atitude dos profissionais da educação. Portanto, reconhece-se também que a qualidade da educação está intimamente ligada à qualidade de formação dos professores e do seu desenvolvimento profissional ao longo da carreira (OLIVEIRA, 2010).

A formação continuada dos professores deve fazer parte integrante do sistema de ensino e não pode reduzir-se a cursos periódicos de reciclagem ou participação em eventos promovidos pelas secretarias (GADOTTI, 2000). Numa mesma perspectiva, a formação dos professores deve ser entendida como um processo contínuo, começando com a formação inicial e se estendendo ao longo da vida profissional, como base essencial para a promoção de mudança educativa visando a eficácia e qualidade de ensino aprendizagem (GARCIA, 1995).

Buscando-se ir além da formação continuada dos professores, acredita-se também que a melhoria da qualidade da educação compreende e envolve a competência profissional dos diretores escolares e sua capacidade de organizar, orientar e liderar as ações e processos promovidos na escola; processos esses voltados para a promoção da aprendizagem, formação dos alunos e desenvolvimento de competências profissionais dos gestores que lhes permitam assumir de forma efetiva o acervo de responsabilidades inerentes às suas funções (LÜCK, 2009).

Entretanto, tanto os professores como os gestores escolares devem receber uma formação, apoio institucional e um acompanhamento adequado para construir novas competências que serão pertinentes nos ciclos de aprendizagem. Por outro lado, todo e qualquer professor dedicado, que ama sua profissão, que respeita seus alunos e é assíduo nas atividades, terá pouco êxito no trabalho profissional se não apresentar as qualidades e competências consideradas ideais para um profissional, pois, a qualidade dos resultados de aprendizagem é inseparável da sua qualificação e competência profissional, sendo que a construção e o fortalecimento da identidade profissional devem fazer parte do currículo e das práticas de formação inicial e continuada (LIBÂNEO, 2013).

Nesse contexto, a formação profissional deve ser contínua, seus saberes e aptidões, sua capacidade de discernir e agir, contemplando a reflexão sobre os valores de educação, vivência interdisciplinar, trabalho em equipe, pesquisa e construção de competências (ZULLIAN; FREITAS, 2001).

É possível reconhecer que a qualidade da educação baseia-se nas competências dos seus profissionais e que, consequentemente, oferecem aos seus alunos e à sociedade em geral experiências educacionais formativas, capazes de promover o desenvolvimento de conhecimentos, habilidades e atitudes, fatores esses necessários para enfrentar os desafios vivenciados em um mundo globalizado, tecnológico, orientado por um acervo cada vez maior e complexo de informações e pela procura de qualidade em todas as áreas de atuação (LÜCK, 2009).

A partir desse contexto, define-se competência como um conjunto de conhecimentos, habilidades e atitudes que justificam um alto desempenho fundamentado na inteligência e personalidade das pessoas, como também 
designada pela capacidade de mobilizar vários recursos cognitivos para enfrentar um tipo de situação. Para os profissionais, a competência deve ser percebida no saber agir de forma responsável e reconhecida, que mobiliza, integra, transfere conhecimentos, recursos e habilidades, que agreguem valor econômico à organização e valor social ao indivíduo (BOYATZIS, 1982; PERRENOUD, 2000; FLEURY; FLEURY, 2001).

A capacidade contínua de desenvolver a competência profissional constitui uma condição fundamental da qualidade de ensino (LÜCK, 2009). De acordo com a autora, escola alguma pode ser melhor do que os profissionais que atuam sobre ela e nenhum ensino pode ser de qualidade para todos se não basear-se em padrões de qualidade e competências profissionais básicas. Assim sendo, quando a organização em questão é uma escola e, por sua vez, essa escola pertence ao sistema público, as competências gerenciais ganham um contorno específico, fazendo com que as competências dos diretores adquiram um sentido próprio no seu cotidiano (GALVÃO; SILVA; SILVA, 2012).

Os padrões de qualidade estabelecem parâmetros necessários para orientar e promover o desenvolvimento de uma organização e seus resultados. Todo e qualquer profissional exerce um conjunto de funções associadas entre si e para que tais funções sejam desenvolvidas deve-se ter funcionários que possuam conhecimentos, habilidades e atitudes específicas e serem articuladas entre si, para ser levado adiante o processo de ensino e aprendizagem nas escolas (LÜCK, 2009; LIBÂNEO, 2013).

Nos estudos de Galvão, Silva e Silva (2012) apresentam-se três padrões de competências dos diretores, respectivamente: técnicas, sociais e comportamentais. As competências técnicas estão relacionadas com a capacidade de aplicar, transferir, generalizar o conhecimento, reconhecendo e definindo problemas. As competências comportamentais, por sua vez, caracterizam a personalidade do indivíduo (demonstrando o espírito empreendedor, capacidade de inovação, iniciativa e liderança). Por último, relaciona a competência social com a atitude que cria um elo entre o particular e o coletivo, promovendo articulações que agreguem valor ao ambiente e ampliem as possibilidades de aprendizagem do indivíduo da organização.

Segundo Perrenoud $(2000,2004)$, são também reconhecido dez domínios de competências como prioritárias na formação contínua dos professores de ensino fundamental, nomeadamente: organização e direção de situaç̃̃es de aprendizagem; administração da progressão da aprendizagem; concepção e evolução dos dispositivos de diferenciação; envolvimento dos alunos em sua aprendizagem e em seu trabalho; trabalho em equipe; participação da administração da escola; informação e envolvimento dos pais; utilização de novas tecnologias; enfrentamento dos deveres e os dilemas éticos da profissão; e administração da sua própria formação contínua.

Lück (2009), traz a reflexão sobre a adoção de uma orientação voltada para o desempenho de competências do trabalho, apresentadas pelo diretor escolar, professor ou pretendente ao exercício da mesma função, baseado em três passos:

1. Ter uma visão abrangente do seu trabalho e do conjunto das competências necessárias;

2. Estabelecer um programa para o desenvolvimento das competências necessárias;

3. Definir uma lista específica de competências para poder avaliar diariamente o seu desempenho.

Nesse contexto, foi possível compreender que a qualidade de uma escola está diretamente ligada à qualidade dos seus profissionais e, nesse sentido, professores e diretores precisam compreender o caminho correto para o desenvolvimento destes profissionais, permitindo que todos entendam as necessidades que cada função exige e a necessidade de aprimoramento; percebam a forma como cada uma das funções será monitorada ou controlada, a fim de permitir que o ciclo de aprendizagem seja totalmente interligado.

\section{METODOLOGIA}

Para responder ao problema e aos objetivos propostos na pesquisa, optou-se pela abordagem qualitativa sem a elaboração de pressupostos a serem analisados, na qual se limitou em fazer uma descrição precisa da situação e procurar descobrir ideias e soluções na tentativa de obter maior clareza com o tema em análise. Como técnica para coleta de dados utilizou-se instrumentos qualitativos (entrevistas semiestruturadas e pesquisa documental).

Foi realizado um estudo com os profissionais da área da educação no nível básico em instituições de ensino primário público de Moçambique, localizadas na cidade da Beira, caracterizando-se como estudo de casos múltiplos, realizado em três instituições de ensino primário e público (YIN, 2010). 
O modelo adotado para estudo teórico e empírico baseou-se na perspectiva de alguns autores em relação aos atributos de qualidade, adaptados e enquadrados às dimensões de qualidade de educação de Dourado, Oliveira e Santos (2009). Dessa forma, apresentados pelos autores como extraescolar e intraescolar pode resumir na Figura 1, que ao mesmo tempo expõe o framework adotado na pesquisa.

Figura 1 - Framework da pesquisa

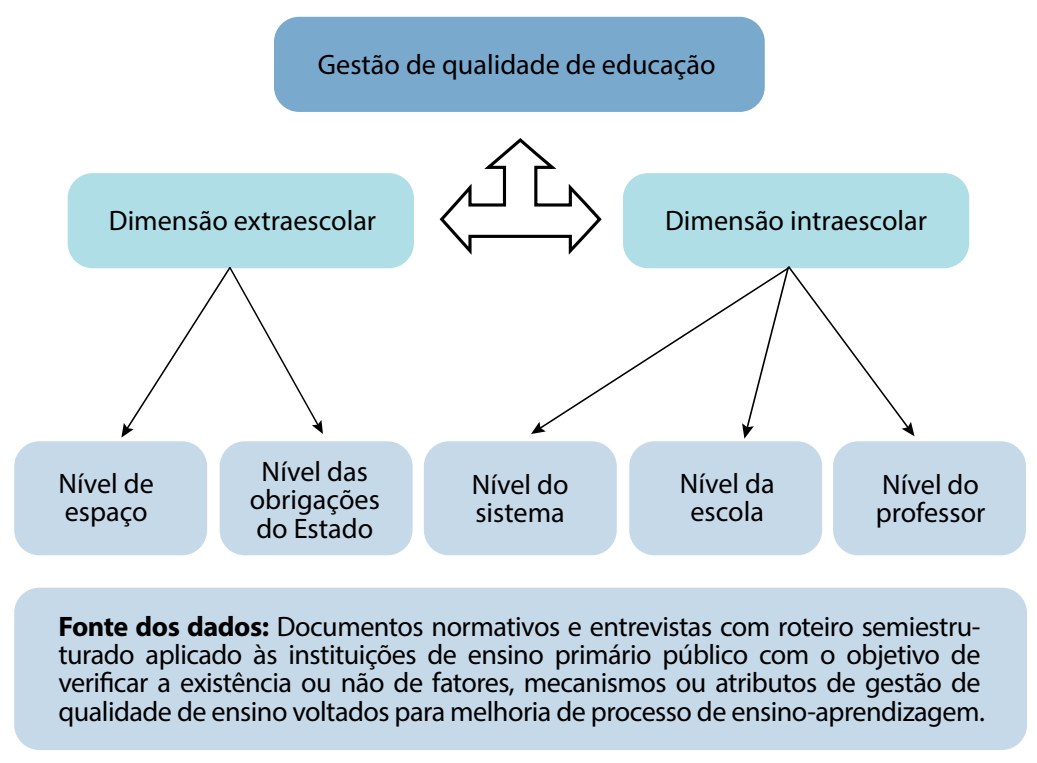

Fonte: Dados da pesquisa (2014).

Conforme os objetivos traçados, o estudo busca identificar nas instituições de ensino características relevantes que possam contribuir para a melhoria de gestão de qualidade de ensino ao nível básico. Essa gestão de qualidade deve ter em conta as dimensões extraescolares e intraescolares, sendo que as mesmas dimensões devem ser interdependentes.

Para a efetivação do estudo recorreu-se a uma amostra não probabilística, onde foram selecionadas três escolas ( $\mathrm{A}, \mathrm{H}$ e $\mathrm{M}$ ) para a realização do estudo. Há que se ter em conta que essas escolas apresentam alguns elementos similares que as aproximam umas das outras, tais como falta de condições de infraestruturas e materiais adequados, orçamento insuficiente, fraca relação professor/aluno na sala de aula e apresentação de um padrão comum de hierarquia de direção, elementos esses que justificaram a escolha das mesmas.

A amostra é constituída por 24 pessoas, sendo seis do corpo diretivo e 18 professores, divididos em oito inquiridos para cada instituição. Os dados foram coletados através de entrevistas com roteiro semiestruturado, sendo que além do roteiro de entrevista utilizou-se também a análise de documentos das instituições em estudo como forma de obtenção dos dados. As entrevistas ocorreram no segundo semestre de 2013, com duração de aproximadamente duas horas para cada entrevistado.

A análise dos dados consistiu no exame, categorização, tabulação e recombinação das evidências, mantendo o modelo conceitual e as proposições iniciais do estudo como referências (BORGES; HOPPEN; LUCE, 2009). Contudo, a análise dos dados foi mediante o modelo proposto por Freitas e Jabbour (2011).

As categorias que compõem a etapa qualitativa da pesquisa foram obtidas a partir do depoimento ou respostas do corpo diretivo e professores das instituições pesquisadas em torno dos fatores contribuintes e mecanismos de gestão de qualidade da educação em suas instituições.

\section{ANÁLISE E DISCUSSÃO DOS RESULTADOS}

Analisar a educação em Moçambique pressupõe compreender seus antecedentes, desde a época da educação tradicional até os tempos de hoje. A educação tradicional possibilitava que os indivíduos recolhessem todas as influências do meio em que habitavam, para então introduzir no seu modo de pensar, 
comportar e agir, abrindo espaço para uma participação ativa nas atividades e na vida do grupo a que pertencia, transformando-o num modelo padrão que era expresso na maneira de viver, pensar e de ser do próprio membro do grupo (GOLIAS, 1993). A educação estava aberta à coletividade, todos os membros da coletividade tinham o direito de educar as crianças, sendo passada de geração em geração e transmitindo a identidade cultural.

Entretanto, faziam parte da pedagogia tradicional, a ligação íntima de educação com a realidade da vida cotidiana, caráter polivalente, pragmatismos dos métodos e a educação sexual (GOLIAS, 1993). Com a chegada dos portugueses, através da igreja católica, a educação reduzia-se a uma minoria, constituída de duas vertentes diferentes de educação (indígenas e elites), existindo uma grande diferença entre as escolas para "nativos" que ensinavam a "educação indígena" orientada por missionários católicos, e as escolas para "brancos e assimilados", geridas pelo Estado ou entidades privadas. Dessa forma, o ensino caracterizava-se por ser discriminatório, ligado à religião e ao ensino fictício da escolarização obrigatória, caráter urbano da rede escolar e paternalista.

Através do Movimento de Libertação Nacional, em 1962, que culminou com a independência de Moçambique, o governo moçambicano criou a política do direito à educação de todo cidadão nacional e esforçou-se para expandir e renovar o ensino primário para crianças; organização de ações de alfabetização para crianças, jovens e adultos, que se encontravam fora do sistema normal de escolarização; e a formação de quadros quantitativa e qualitativamente para ocorrer a gestão e conduzir o processo educacional, caracterizando-se deste modo por um aumento de efetivos escolares jamais visto na história de educação em Moçambique (GOLIAS, 1993).

Contudo, durante o período entre 1980 e 1990, o país passou por uma fase de instabilidade que se refletiu negativamente em todo território nacional, afetando também a rede escolar, passando o país por uma fase de estagnação do sistema educativo devido às destruições materiais causadas pela guerra civil.

Desde a assinatura de Acordo Geral de Paz, em 1992, o país tem tentado oferecer a educação básica e universal a todas as crianças em idade escolar, fato que se pode observar no crescente número da taxa bruta de admissões que oscilou de menos de 60 para 100\% no período de 1992 a 1999, e no aumento de rede escolar no período de 2000. A figura seguinte ilustra a evolução de número de escolas por níveis de escolaridade desde os anos de 1974 a 2012 (GOLIAS, 1993).

Figura 2 - Evolução de números de escolas por níveis de escolaridade

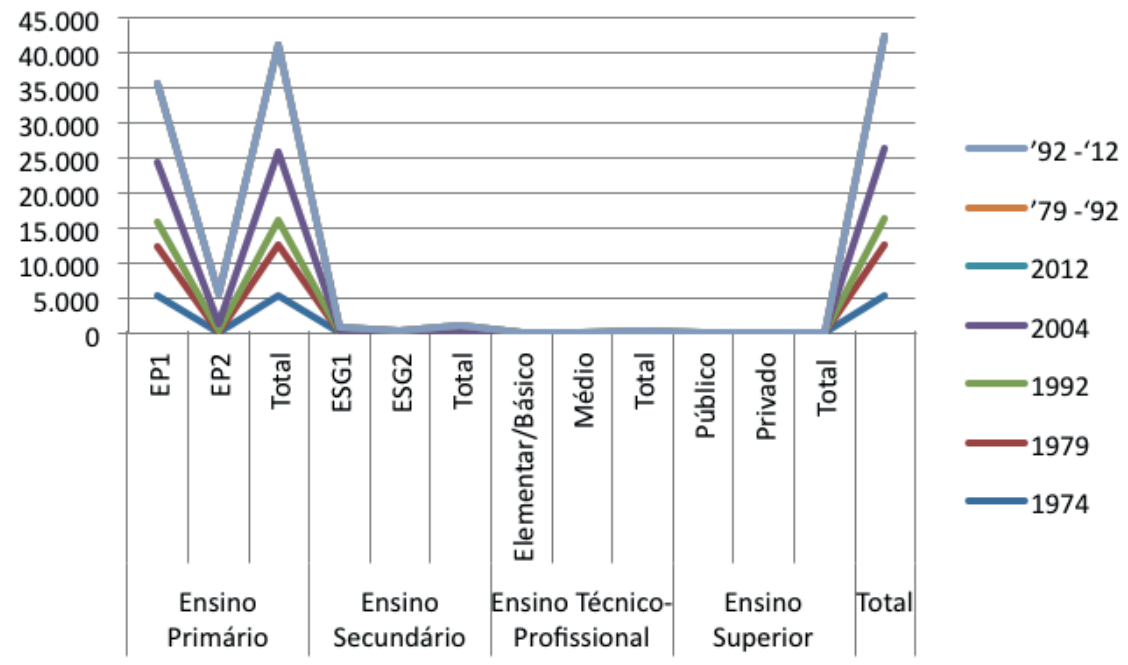

Fonte: Elaborado pelos autores (2014), baseado em Golias (1993).

Em relação aos mecanismos ou atributos de qualidade, as respostas dos diretores apresentam um grande nível de concordância e semelhanças entre si, levando a crer que existe um alinhamento entre os diretores das três instituições pesquisadas em relação à busca de melhoria de qualidade de ensino para atingir os objetivos traçados ao nível do governo central para melhoria de qualidade do processo de ensino aprendizagem. 
Os mecanismos ou atributos de melhoria de qualidade nas instituições de ensino primário, mediante as respostas dos diretores, incidem sobre vários fatores organizacionais, sociais e pessoais (DOURADO; OLIVEIRA; SANTOS, 2009), fatores estes que auxiliam os principais objetivos traçados ao nível do Plano Estratégico da Educação e Cultura 2012/16 (PEEC).

Dependendo do ponto de vista e da realidade de cada uma das escolas, são considerados alguns aspectos como influenciadores da qualidade de educação. Na escola A, são considerados: $1^{\circ}$ gestão/liderança; $2^{\circ}$ ética no trabalho, participação da comunidade, gestão democrático-participativa e condições materiais de trabalho; $3^{\circ}$ satisfação profissional, formação e política de orientação ao aluno. Na escola $\mathrm{H}$, são considerados: $1^{\circ}$ supervisão pedagógica; $2^{\circ}$ gestão/liderança; $3^{\circ}$ formação. Na escola $M$, são considerados: $1^{\circ}$ formação; $2^{\circ}$ política de orientação ao aluno; $3^{\circ}$ satisfação profissional e formação, ética no trabalho, participação comunitária, gestão democrático-participativa e condições de trabalho.

De acordo com o Plano Estratégico da Educação e Cultura (PEEC 2012/16), a melhoria de qualidade incide sobre a inclusão e equidade no acesso e retenção na escola, privilegiando a universalização do ensino de $7^{a}$ classe, com foco na aprendizagem, desenvolvimento de competências básicas (leitura, escrita e cálculos) e na garantia de um bom governo do sistema educativo.

Como forma de avaliar o processo de melhoria de qualidade nas instituições, verificar e controlar o rendimento escolar e, consequentemente, melhorar o ensino aprendizagem dos alunos do ensino básico, as instituições de ensino utilizam vários procedimentos e instrumentos de mensuração previstos nos vários documentos normativos de conduta da escola (provas, exercícios teóricos e práticos, tarefas de casa). Essas são ações estratégicas rumo à qualidade de educação, na medida em que faz parte de todo um conjunto de decisões e ações com o objetivo de garantir a consistência interna e externa da organização, movimentando todos os recursos (ESTEVÃO, 1998).

Contudo, para uma boa gestão e melhoria na qualidade da educação, associam-se fatores sociais e comunitários, chamando e incluindo a comunidade na gestão participativa e direção coletiva das escolas, uma vez que com a gestão participativa é concedida à comunidade a oportunidade de participar na gestão da escola através dos Conselhos de Escola (LÜCK, 2009).

Com a inclusão da comunidade na gestão e administração da escola, o governo procura buscar uma forte parceria entre a escola e a comunidade/sociedade, estimulando iniciativas de aproveitamento de recursos para ultrapassar as dificuldades encontradas nas escolas. Essa inclusão pode ser realizada de forma informal e esporádica, mas deve-se ter atenção aos procedimentos sistemáticos e organizacionais promovidos por meio de parcerias na educação, de modo que se obtenham os resultados almejados (LÜCK, 2009).

A relação entre escola e comunidade poderá influenciar em uma boa gestão, mas se fará presente a partir do momento em que os diretores escolares concederem um espaço e reconhecerem o significado da gestão participativa. Como já referenciado, o direito à educação não é apenas responsabilidade e ou obrigação do Estado, mas sim de todos (pais e encarregados de educação, família, comunidade, organizações não governamentais e parceiros internacionais). Cada um possui um papel a desempenhar, na oferta e procura de serviços educativos dentro das suas capacidades e meios em função das necessidades, porém fazendo valer a igualdade e condição de acesso à educação.

Nessa perspectiva, a escola não deve ser vista como uma instituição isolada, mas sim integrada numa comunidade que interage com a vida social mais ampla. As atuais formas de interação entre a escola e a comunidade exigem cada vez mais a participação dos pais na organização e gestão da escola, criando práticas de descentralização, autonomia, corresponsabilização e interculturalismo (LIBÂNEO, 2013).

As constatações da pesquisa, em geral, mostram que a busca pela melhoria da qualidade na educação básica nas escolas moçambicanas é complexa. Por um lado, o governo está comprometido em empreender esforços e continuar a assegurar uma educação universal de sete classes para todas as crianças em idade escolar e com qualidade, pois, acredita na educação como chave para o futuro desenvolvimento e sucesso do país, e esperam desempenhar seu papel.

Por outro lado, as escolas não têm os meios e as condições necessárias para cumprir o seu papel, sendo apontado pelos membros de direção das instituições pesquisadas um número considerável de fatores que se inter-relacionam (organizacionais, sociais e pessoais) e que devem ser levados em conta, visto que de alguma forma impedem a aplicação das suas habilidades para um bom desempenho das suas funções. 
Joana Carlos Beira; Sandra M. Lohn Vargas; Cláudio Reis Gonçalo

Um dos fatores importantes apontados pelos diretores baseia-se na falta de material didático, considerado uma difícil missão no momento de ensinar os alunos. A qualidade de ensino é afetada por recursos e infraestruturas não adequadas, fazendo com que os alunos não consigam progredir como deveriam, além de aumentar a desmotivação e a falta de autoestima dos professores, deixando-os preocupados em não realizarem o seu trabalho como gostariam, por falta de meios e condições de trabalho. Estas questões enfatizam as propostas de Xavier (1996) e Longo (1996) que apontam o gerenciamento dos aspectos envolvidos como motivação intrínseca e extrínseca dos profissionais de educação, bem com as dimensões extraescolar e intraescolar (DOURADO; OLIVEIRA; SANTOS, 2009).

A qualidade na educação básica também depende do fator formação, desempenho do corpo docente, satisfação pessoal e profissional, e é considerado como uma base para aumentar a autoconfiança e competência na sala de aula. Entretanto, sente-se um grande esforço empreendido ao nível do governo para tentar solucionar os problemas, verificando-se um plano de formação que tende a enquadrar todo o docente e não docente para a continuação dos seus estudos como uma das formas para melhorar a qualidade de ensino.

Através do programa de apoio direto às escolas, com vista a criar condições necessárias para um ambiente escolar saudável e propício para a aprendizagem dos alunos, são disponibilizados a cada ano professores, livros e recursos financeiros às escolas. Como também definidas estratégias integradas de formação e capacitação dos professores, inicial e em serviço, de acordo com o novo paradigma "formação baseada em competências" (MOÇAMBIQUE, 2012).

A questão da supervisão pedagógica e políticas de orientação ao aluno também fazem da escola um diferencial. Todavia, toda e qualquer atividade escolar necessita de um acompanhamento com vista a atingir os objetivos pretendidos. A supervisão traz uma maior interação e parceria dos envolvidos no Processo de Ensino Aprendizagem (PEA), orientando e organizando o trabalho pedagógico desenvolvido na escola.

De acordo com Libâneo (2013), há algum tempo muitos dirigentes escolares já foram alvo de críticas, devido às práticas excessivas de burocracia, conservadoras, autoritárias e centralizadoras, embora existam ainda casos parecidos de profissionais com o mesmo perfil, hoje já se dissemina a prática de liderança participativa. A figura do diretor da escola pressupõe a maior responsabilidade pela escola, porém deve ter uma visão de conjunto, isto é, articulação e integração de vários setores.

Finalizando, aspectos como a ética no trabalho, a capacidade de saber ouvir, de aprender a agir com respeito, solidariedade, justiça, o diálogo em todas e diferentes situações, são valores e atitudes que se deve aprender e desenvolver nas escolas e serem repassados aos alunos. A escola é um meio de interação social, com isso, devemse criar meios de incorporar a ética e a cidadania no cotidiano das salas de aula e na vida dos alunos, com vista à formação de atitudes éticas e morais de todos os membros que nela atuam. Para isso a conduta do professor deve servir de espelho e por isso deve ser assíduo, pontual, comprometido com a atividade que realiza e dedicado, como aponta e complementa o diretor Adjunto Pedagógico e o diretor da escola M.

Na percepção dos diretores e professores, a incessante busca pela melhoria da qualidade no ensino básico reflete-se na boa liderança e gestão participativa de todos os envolvidos no processo de ensino aprendizagem, condições de trabalho, formação e qualificação docente, supervisão pedagógica, ética no trabalho, satisfação profissional e política de orientação ao aluno, também são aspectos que complementam, segundo Dias (2001) e Donel et al. (2001).

\section{CONCLUSÃO}

O artigo buscou analisar a gestão de qualidade do ensino básico de Moçambique como forma de contribuir para a melhoria no processo de ensino aprendizagem em três instituições de ensino primário. Procurou-se refletir aspectos que contribuam para avaliação da qualidade do ensino básico em Moçambique por meio de processos de gestão, como o papel dos diretores, professores e a comunidade em geral na contínua busca de melhoria de qualidade educacional.

Há que se observar que a gestão da qualidade de educação é um processo no qual se exige a participação e o envolvimento de todas as pessoas e da sociedade em geral. Os dados apresentados levam à constatação 
que a questão da qualidade de educação é um fenômeno complexo, bem como interdependente entre vários aspectos do ambiente interno e externo da escola.

Dessa forma, foi possível identificar um processo interativo entre a comunidade escolar e a comunidade circunvizinha, manifestando-se assim práticas de gestão participativa para se atingir uma qualidade de educação. Os resultados transparecem um sistema de educação que tende a mudanças, caminhando em busca de um sistema de educação para todos, que abrange todas as crianças em idade escolar que ainda se encontram fora do sistema educativo também.

Existe nas escolas uma percepção do quão importante é a participação e o envolvimento de toda comunidade, para o bom funcionamento da instituição, por se acreditar que todos fazem parte da vida da escola e nada se pode fazer para alcançar a qualidade de educação sem que os próprios professores, alunos e familiares contribuam.

Constatou-se que dentre vários fatores relativos à melhoria na qualidade de educação, as questões de gestão/liderança, ética no trabalho, participação da comunidade, gestão democrático-participativa, condições materiais de trabalho, satisfação profissional, formação, orientação para os alunos e supervisão pedagógica são aquelas que apresentaram um maior destaque.

Dessa forma, requer uma estratégia e busca de soluções para melhorar cada um dos fatores estudados, levando a direção escolar, junto ao governo e à comunidade, a desenvolver um trabalho de mobilização e sensibilização sem medir esforços para investimento e planejamento, formação e sistemas melhorados em todos os níveis, assim como recursos.

Tornou-se evidente que para se atingir uma boa qualidade de educação aspectos como estratégia, gestão e formação devem estar presentes e interligados. Nesse sentido, como recomendação, os aspectos apresentados em seguida resumem os comentários descritos no decorrer da análise:

- Garantir e melhorar as condições de trabalho dos profissionais de educação;

- Reforçar a formação inicial e em serviço, numa perspectiva de formação contínua do pessoal docente e não docente;

- Garantir o cumprimento da supervisão pedagógica;

- Sensibilizar cada vez mais a participação dos pais e encarregados de educação e a comunidade em geral na vida da escola e fazer conhecer seus direitos e obrigações;

- Desenvolver mecanismos nas escolas que sejam eficazes, voltados para avaliação interna de qualidade de educação, processo que pode ser holístico e ampliar os estudos sobre a qualidade da educação no país, a fim de se identificarem as estratégias mais adequadas para a redefinição dos currículos de formação de professores.

Neste sentido, acredita-se que o estudo possa contribuir para que se tenha uma perspectiva da qualidade do ensino aprendizagem em Moçambique, em particular nas três escolas que foram objeto do estudo. $O$ mesmo poderá contribuir com os legisladores de políticas educacionais, sejam de nível central, provincial ou distrital, bem como de Organizações Não Governamentais (ONG's) e associações nacionais e estrangeiras que atuam na área da educação.

Considera-se que com a pesquisa não foi possível esgotar a totalidade de assuntos relacionados com a questão da gestão de qualidade, propondo-se que estudos futuros tomem em consideração os seguintes aspectos: (i) explorar o tema em outros subsistemas de ensino, como o secundário, técnico-profissional e o superior; (ii) ampliar estudos a outras cidades e zonas rurais de Moçambique; (iii) analisar as mudanças previstas em andamento através de pesquisa longitudinal, permitindo descrever e analisar a transição que possa vir a ocorrer. 


\title{
BASIC EDUCATION QUALITY MANAGEMENT IN MOZAMBIQUE: A STUDY IN PRIMARY AND PUBLIC SCHOOLS
}

\begin{abstract}
This paper analyzes the quality management of basic education in Mozambique as a contribution to improving the teaching-learning process in three primary educational institutions. Teachers and principals focusing on content analysis and official documents of the Mozambican government were surveyed.

Data was collected through semi-structured interviews, following the qualitative approach. The variables analyzed were quality mechanisms, competence of principals and teachers as well as their profile and training. The results point to the factors that are relevant to improve the quality of education such as: more effective policies for guidance to the student, continuous and integrated training for teachers and school professionals, working conditions, democratic-participatory management and implementation of an evaluation system. The study showed that better management is important for optimum performance of schools and students, requiring from directors efforts to better control and analyse the process inside and outside the classroom.
\end{abstract}

Keywords: Quality Management. Basic Education. Mozambique. Primary school.

\section{REFERÊNCIAS}

ANDRÉ, Marli E. D. A. Formaação de professores: a constituição de um campo de estudos. Educação, Porto Alegre, v. 33, n. 3, p. 174-181, set./dez. 2010.

BORGES, Mauro; HOPPEN, Norberto; LUCE, Fernando Bins. Information technology impact on market orientation in e-business. Journal of Business Research, Athens, GA, USA, v. 62, p. 883-890, set. 2009.

BOYATZIS, Richard E. The competent manager: a model for effective performance. New York: John Wiley\& Sons, 1982.

DEMO, Pedro. Educação e qualidade. 3. ed. Campinas: Papirus, 1996.

DIAS, Miriam Fernandes Xavier. Qualidade na educação. Vértices, Campos dos Goytacazes, RJ, v. 3, n. 1, p. 1-20, 2001.

DONEL, Flavia et al. Qualidade na Educação. In: COBENGE - CONGRESSO BRASILEIRO DE ENSINO DE ENGENHARIA, 24, 2001, Uberlândia. Anais..., Uberlândia, MG: UFU, 2001.

DOURADO, Luiz Fernandes; OLIVEIRA, João Ferreira de. A qualidade da educação: perspectivas e desafios. Brasília: MEC/INEP, 2007.

DOURADO, Luiz Fernandes; OLIVEIRA, João Ferreira de; SANTOS, Catarina de Almeida. A Qualidade da Educação: conceitos e definições. Cad. Cedes, Campinas, v. 29, n. 78, p. 201-215, maio/ago. 2009.

EDUARDO, Tomé. Moçambique: a prestação efectiva de serviços públicos no sector da Educação. África do Sul: Open Society Foundations, 2012.

ESTEVÃO, Carlos. Gestão estratégica nas escolas. Lisboa: Instituto de Inovação Educacional, 1998. (Cadernos de Organização e Gestão Curricular).

FLEURY, Maria Tereza Leme; FLEURY, Afonso. Construindo o conceito de competência. RAC, Rio de Janeiro, p.183-196, 2001. Edição Especial. 
FONTANIVE, Nilma Santos; KLEIN, Rubén. O efeito da capacitação docente no desempenho dos alunos: uma contribuição para a formulação de novas políticas públicas de melhoria na qualidade da educação básica. Revista Iberoamericana de Evolução Educativa, Portugal, v. 3, n. 3, p. 62-89, 2010.

FREITAS, Wesley R. S.; JABBOUR, Charbel J. C. Utilizando estudo de caso(s) como estratégia de pesquisa qualitativa: boas práticas e sugestões. Estudo \& Debate, Lajeado, v. 18, n. 2, p. 07-22, 2011.

GADOTTI, Moacir. Perspectivas atuais da educação. Porto Alegre: Artes Médicas Sul, 2000.

GADOTTI, Moacir. Qualidade na educação: uma nova abordagem. In: CONGRESSO DE EDUCAÇÃO BÁSICA: QUALIDADE NA APRENDIZAGEM, COEB, 1., 2013, Florianópolis. Anais... Florianópolis: COEB, 2013.

GARCIA, Carlos Marcelo. A formação de professores: novas perspectivas baseadas na investigação sobre o pensamento do professor. In: NÓVOA, António (Coord.). Os professores e a sua formação. Lisboa: Publicações Dom Quixote, 1995. p. 51-76.

GARVIN, David A. Gerenciando a qualidade: a visão estratégica e competitiva. Rio de Janeiro: Qualitymark, 1992.

GOLIAS, Manuel. Sistema de ensino em Moçambique, passado e presente. Moçambique: Escolar, 1993.

LIBÂNEO, José Carlos. Organização e gestão da escola: teoria e prática. 6. ed. São Paulo: Heccus Editora, 2013.

LONGO, Rose Mary Juliano. Gestão da qualidade: evolução histórica, conceitos básicos e aplicação na educação. Brasília: Instituto de Pesquisa Econômica Aplicada, 1996.

LÜCK, Heloísa. Dimensões de gestão escolar e suas competências. Curitiba: Positivo, 2009.

MICHELS, Maria Helena. Gestão, formação docente e inclusão: eixos da reforma educacional brasileira que atribuem contornos à organização escolar. Revista Brasileira de Educação, Rio de Janeiro, v. 11, n. 33, p. 406-423, set./dez. 2006.

MOÇAMBIQUE. Ministério da Educação e Cultura de Moçambique. Plano estratégico de educação 20122016. Maputo: MEC, 2012.

NÓVOA, António. (Coord.). Os professores e a sua formação. Lisboa: Publicações Dom Quixote, 1995.

OLIVEIRA, Ana Margarida Massa de. Experiências de supervisão pedagógica: contributos para o desenvolvimento profissional dos professores cooperantes do $1^{\circ}$ Ciclo do Ensino Básico. 2010. Dissertação (Mestrado em Supervisão Pedagógica) - Universidade dos Açores, Ponta Delgada, 2010.

OLIVEIRA, Romualdo Portela de; ARAUJO, Gilda Cardoso de. Qualidade do ensino: uma nova dimensão da luta pelo direito à educação. Revista Brasileira de Educação, Rio de Janeiro, n. 28, p. 5-23, abr. 2005.

PERRENOUD, Philip. Dez novas competências para ensinar. Porto Alegre: Artes Médicas Sul, 2000.

PERRENOUD, Philippe. Os ciclos de aprendizagem: um caminho para combater o fracasso escolar. Porto Alegre: Artes Médicas Sul, 2004.

SLLIS, Edward. Totalquality management in education. 3. ed. London: Kongan Page, 2002. 
STEPHEUS, David. Quality of basic education. [2003]. Paper for EFA Global Monitoring Report. Disponível em: <http://unesdoc. unesco. org/images/0014/001469/146968e>. Acesso em: 14 jun. 2015.

XAVIER, António Carlos da R. A gestão da qualidade e a excelência dos serviços educacionais: custos e benefícios de sua implantação. Brasília: Instituto de Pesquisa Econômica Aplicada, 1996.

YIN, Robert K. Estudo de caso: planejamento e métodos. 4. ed. Porto Alegre: Bookman, 2010.

ZULLIAN, Margaret Simon; FREITAS, Soraia Napoleão. Formação de professores na educação inclusiva: aprendendo a viver, criar, pensar e ensinar de outro modo. Revista Educação Especial, Santa Maria, n. 18, 2001. 